\title{
Atomic ruthenium coordinated with chlorine and nitrogen as efficient and multifunctional electrocatalyst for overall water splitting and rechargeable zinc-air battery
}

Jianfeng Huang

School of Materials Science and Engineering, Shaanxi University of Science and Technology Junsheng Chen

Shaanxi University of Science and Technology

Yongqiang Feng ( $\sim$ fengyq@sust.edu.cn )

Shaanxi University of Science and Technology https://orcid.org/0000-0002-7026-7152

Ran Wang

Xi'an Technological University

\section{Weihang Feng}

Shaanxi University of Science and Technology

Hai Wang

Shaanxi University of Science and Technology

Tianmi Luo

Shaanxi University of Science and Technology

Yuzhu Hu

Shaanxi University of Science and Technology

Chengke Yuan

Shaanxi University of Science and Technology

\section{Liangliang Feng}

Shaanxi University of Science and Technology

\section{Koji Kajiyoshi}

Kochi University https://orcid.org/0000-0002-8100-6791

Chaozheng He

Xi'an Technological University

\section{Liyun Cao}

Shaanxi University of Science and Technology

Article 
Keywords: ruthenium, single-atom catalyst, overall water splitting, zinc-air battery

Posted Date: September 8th, 2021

DOI: https://doi.org/10.21203/rs.3.rs-870874/v1

License: (c) (1) This work is licensed under a Creative Commons Attribution 4.0 International License. Read Full License 


\section{Abstract}

Design and fabrication of multifunctional efficient and durable single atom electrocatalyst is highly desirable and challenging for overall water splitting and zinc-air battery. Herein, a novel and efficient ruthenium coordinated with $\mathrm{Cl}$ and $\mathrm{N}$ single atom catalyst (Ru-Cl-N SAC) was synthesized. X-ray adsorption spectroscopy combined with theoretical calculation results unveiled an atomic configuration of $\mathrm{RuCl}_{2} \mathrm{~N}_{2}$. Electrochemical measurement disclosed that the $\mathrm{Ru}-\mathrm{Cl}-\mathrm{N} \mathrm{SAC}$ exhibited superior electrocatalytic activities toward hydrogen evolution reaction (HER), oxygen evolution reaction (OER) and oxygen reduction reaction (ORR) with low overpotential and long-term durability in alkaline medium. Furthermore, a well-qualified assembly of overall water splitting cell requiring only $1.49 \mathrm{~V}$ to achieve a current density of $10 \mathrm{~mA} \mathrm{~cm}^{-2}$ and a rechargeable zinc-air battery with a specific capacity of $804.26 \mathrm{mAh}$ $\mathrm{g}^{-1}$ and long-term durability for $360 \mathrm{~h}$ were fabricated based on the $\mathrm{Ru}-\mathrm{Cl}-\mathrm{N} \mathrm{SAC}$. The present work would pave the way for design and fabrication of novel and efficient multifunctional electrocatalyst in the realm of energy conversion and storage.

\section{Main Text}

Developing clean and sustainable energy conversion and storage technologies (ECST), including water electrolysis, metal-air batteries, fuel cells, etc., have gained extensive attention due to their environmentally friendly and high efficiency ${ }^{1,2,3}$. However, electrocatalysts associated with hydrogen evolution reaction (HER), oxygen evolution reaction (OER) and oxygen reduction reaction (ORR) are required owing to the sluggish reaction kinetics involved in such ECST-based devices ${ }^{4,5,6,7}$. It is wellknown that HER and OER are two main half-cell reactions in water splitting to convert electric energy to hydrogen and oxygen resources ${ }^{8}$, while OER and ORR work in the cathode of metal-air batteries to generate electric from chemical energy ${ }^{9}$. Nevertheless, the state-of-the-art electrocatalysts such as commercial Pt/C, $\mathrm{RuO}_{2}$ and $\mathrm{IrO}_{2}$ are unable to drive two electrochemical processes simultaneously by themselves in water splitting and/or metal-air batteries, not to mention their insufficient electrocatalytic durability ${ }^{10,11}$. Therefore, it is desirable and indispensable to design and construct viable alternative materials with bifunctional or even multifunctional electrocatalytic performance to promote the integration of ECST-related devices.

In the past two decades, a myriad of efforts has been dedicated to develop versatile nanomaterials used

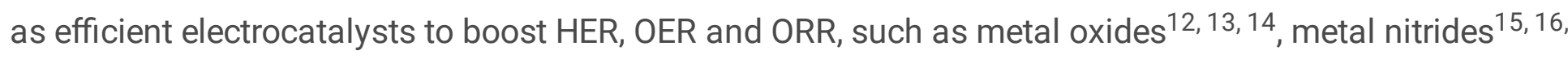
17 , metal phosphides ${ }^{18,19,20}$, metal alloys ${ }^{21,22,23}$, metal cluster and single atom-site catalysts (SACs) ${ }^{24}$, $25,26,27,28,29,30$, etc. Notably, the SACs have possessed the leading position in the field of water splitting and metal-air batteries ${ }^{31}, 32$, since they combine the merit of heterogenous and homogenous catalysts with maximized atom utilization and highly active sites $^{33,34}$. It is established that the performance of SACs is rather susceptible to their structures $22,28,35,36,37,38$, e.g., geometric and electronic configurations, dispersion state and coordination environment. Xiao et al. ${ }^{28}$ recently demonstrated that the spontaneous 
bonding of $\mathrm{OH}$ to $\mathrm{RuN}_{4} \mathrm{SAC}$ could regulate the energy level of Ru and result in an appropriate adsorption free energy of $\mathrm{OH}^{\star}$, conferring excellent ORR catalytic activity and long-term durability. Another Ru SAC coordinated with nitrogen and carbon $\left(\mathrm{RuC}_{2} \mathrm{~N}_{2}\right)$ serving as efficient HER catalyst in alkaline medium ${ }^{29}$, reported by Lu et al., exhibited much lower hydrogen binding energy than Ru nanoparticles (NP) and a lower kinetic barrier for water dissociation than Pt. Beside N and O, heteroatoms (e.g., B, S, P, F) with different electronegativities are generally considered as sustenance of catalysts to spark their thermodynamic potential by modulating the electronic configuration $39,40,41$. Of these, halogen atoms such as chlorine have cast varieties of interest due to their unique electron-donation properties, and thus halide catalysts have been widely utilized in organic synthesis (hydrogen addition, $\beta$ hydride elimination, ammonia borane dehydrogenation $)^{42,43,44}$, photocatalytic reaction ( $\mathrm{CO}_{2}$ reduction, hydrogen evolution, organic contaminant degradation) ${ }^{45,46,47}$ and electrocatalytic reaction (HER, OER, ORR, $\mathrm{N}_{2}$ reduction) ${ }^{48,}$ ${ }^{49}$. However, metal-halogen coordinated SACs have been rarely reported despite of SACs are emerging as a rising star for these above-mentioned reactions.

Herein, we developed a $\mathrm{Cl}, \mathrm{N}$-bonded $\mathrm{Ru}(\mathrm{Ru}-\mathrm{Cl}-\mathrm{N}) \mathrm{SAC}$ serving as multifunctional electrocatalyst for HER, OER and ORR, which was obtained by anchoring ruthenium chloride molecules in the cavity of cobalt-based zeolitic imidazolate framework (ZIF-67) template, followed by thermal pyrolysis and acid etching of cobalt ions and unstable ruthenium species. X-ray synchrotron radiation adsorption spectrum combined with density functional theory (DFT) calculation results unveiled an optimized coordination configuration of $\mathrm{RuCl}_{2} \mathrm{~N}_{2}$. Electrochemical measurements demonstrated this novel Ru-Cl-N SAC exhibited highly efficient electrocatalytic performance with an overpotential of as low as $12 \mathrm{mV}$ for HER, and $233 \mathrm{mV}$ for OER to deliver a current density of $10 \mathrm{~mA} \mathrm{~cm}^{-2}$ and half-wave potential $\left(\mathrm{E}_{1 / 2}\right)$ of $0.90 \mathrm{~V}$ versus the reversible hydrogen electrode (RHE) for ORR. Benefiting from the superior multifunctional electrocatalytic performance, a well-qualified assembly of overall water splitting cell requiring low potential of $1.49 \mathrm{~V}$ at $10 \mathrm{~mA} \mathrm{~cm}{ }^{-2}$ and a rechargeable $\mathrm{Zn}$-air battery with a specific capacity of 804.26 $\mathrm{mAh} \mathrm{g}^{-1}$ and long-term stability for $360 \mathrm{~h}$ was achieved. As far as we know, this is the first report on the design and construction of $\mathrm{Cl}, \mathrm{N}$-coordinated Ru single-atom multifunctional electrocatalyst that enables the boosting of overall water splitting and Zn-air battery.

\section{Results}

Synthesis and Characterization of Ru-Cl-N SAC. Ruthenium chloride $\left(\mathrm{RuCl}_{3}\right)$ molecules as the ruthenium and chlorine resource were initially incorporated into the cavity of ZIF-67 via solvothermal reaction (Scheme 1), followed by pyrolysis (according to the TG-DSC curve, Supplementary Fig. S1) and acid etching of cobalt nanoparticles and unstable Ru species. From the scanning electron microscope (SEM) and transmission electron microscope (TEM) images as shown in Fig. 1a, b, the pyrolyzed product RuCl-N SAC inherits the polyhedral morphology of the as-synthesized CoRu-ZIF-67 (Supplementary Fig. S2). Besides, numerous nanopores could be observed in $\mathrm{Ru}-\mathrm{Cl}-\mathrm{N} \mathrm{SAC}$, which would facilitate the diffusion process of electrolyte and gas bubbles generated during the electrochemical reaction ${ }^{50}$. 
Selected area electron diffraction (SAED) image (Fig. 1c) derived from the marked circle in Fig. 1b indicates the formation of graphitic carbon with typical diffraction rings of (002) and (200) crystal lattice ${ }^{51}$. No Co-based nanoparticles, which was obviously present in the pyrolysis of $\mathrm{Ru}-\mathrm{Cl}-\mathrm{N} \mathrm{SAC}$ product (defined as Co NP/ Ru-Cl-N SAC, Supplementary Fig. S3), were found during the TEM observation. Two broad peaks observed at 25.3 and $43.8^{\circ}$ in the X-ray diffraction (XRD) pattern (Fig. 1d) can be assigned to the (100) and (002) plane of carbon substrate ${ }^{52,53}$, which coincided with the TEM result. Raman spectrum (Fig. 1e) of Ru-Cl-N SAC shows D and G band located at 1181 and $1428 \mathrm{~cm}^{-1}$, respectively, with an $I_{D} / I_{G}$ intensity ratio of 0.99 , indicating the presence of rich defects existed in the carbon matrix ${ }^{35}$. The specific surface area and pore volume (Fig. 1f) are determined to be $253.02 \mathrm{~m}^{2} \mathrm{~g}^{-1}$ and $0.22 \mathrm{~cm}^{3} \mathrm{~g}^{-1}$, respectively. According to the pore size distribution analysis, most of the nanopores are centered at 1.9 and $3.3 \mathrm{~nm}$. The TEM and XRD results implied that Ru may exist in the form of single atom state. To conform this point, aberration-corrected high-angle-annular-dark-field scanning transmission electron microscopy (AC-HAADF-STEM) was employed. A large number of bright dots depicted in Fig. 1g, which represent single atom, can be clearly seen. The elemental mapping displayed in Fig. $1 \mathrm{~h}$ further verified the uniform distribution of $\mathrm{Ru}, \mathrm{Cl}$ and $\mathrm{N}$ on the surface of carbon substrate.

To throw insight to the local coordination environment, chemical states and structure features within $\mathrm{Ru}-$ Cl-N SAC, highly sensitive X-ray adsorption fine spectroscopy (XAFS) experiments including the extended X-ray adsorption fine spectroscopy (EXAFS) were carried out ${ }^{29,54,55}$. Fig. 3a shows the Ru K-edge X-ray adsorption near-edge structure (XANES) spectrum of $\mathrm{Ru}-\mathrm{Cl}-\mathrm{N} \mathrm{SAC}$, Ru foil, $\mathrm{RuCl}_{3}$ and $\mathrm{RuO}_{2}$. The adsorption location of $\mathrm{Ru}-\mathrm{Cl}-\mathrm{N} \mathrm{SAC}$ was slightly higher than that of Ru foil and lower than those of $\mathrm{RuCl}_{3}$ and $\mathrm{RuO}_{2}$, indicative of a chemical state between 0 and +3 (ref. 35). Impressively, the valley in the range of $22125-22148 \mathrm{eV}$ originated from Ru-N/O was slightly blue-shifted, which may be attributed to the bonding with $\mathrm{Cl}$. The coordination environment of $\mathrm{Ru}-\mathrm{Cl}-\mathrm{N}$ was further revealed by Fourier-transform (FT) $k^{2}$-weighted EXAFS spectrum of Ru K edge. As shown in Fig.3b, the dominant coordination peak located at $1.97 \AA$ for $\mathrm{Ru}-\mathrm{Cl}-\mathrm{N} \mathrm{SAC}$ was assigned to Ru-Cl bond of the atomic Ru coordinated with $\mathrm{Cl}$, which was almost overlapped with the peak of $\mathrm{RuCl}_{3}$. While the shoulder peak at $1.5 \AA$ could be ascribed to Ru-N coordination of the atomic Ru bonded with $\mathrm{N}$ in the carbon substrate ${ }^{56}$. Besides, Ru nanoparticles were also observed with a peak located at $2.44 \AA$ in reference to Ru foil. Wavelet transform (WT) was then performed to investigate the Ru K-edge EXAFS oscillations of $\mathrm{Ru}-\mathrm{Cl}-\mathrm{N} \mathrm{SAC}{ }^{30}$. The two dominant peaks were observed at around 6.24 and $8.55 \AA^{-1}$ that can be assigned to atomic Ru-N bond and Ru-Cl bond, respectively. Combined with the AC-HAADF-STEM result, one can safely confirmed that the atomic Ru in $\mathrm{Ru}-\mathrm{Cl}-\mathrm{N} \mathrm{SAC}$ was coordinated with $\mathrm{Cl}$ and $\mathrm{N}$ embedded in carbon substrate. Fitting the FT EXAFS spectrum of Ru-Cl-N SAC in R space revealed an average coordination number (CN) of 2.6 for $\mathrm{Ru}-\mathrm{Cl}$ and 2.0 for Ru-N (Supplementary Fig. S4 and Table S1), leading to a chemical formula of $\mathrm{RuCl}_{2} \mathrm{~N}_{2}$. To the best of our knowledge, this is the first report on $\mathrm{Cl}, \mathrm{N}$-coordinated Ru single atom electrocatalyst. Notably, when ruthenium chloride was replaced by ruthenium acetylacetonate, $\mathrm{RuN}_{4} \mathrm{SAC}$ with Ru coordinated with four $\mathrm{N}$ atoms was obtained (Supplementary Fig. S5 and S6). On the other hand, the role of Co was critical in preventing the aggregation of Ru atoms, e.g., when we used ZIF-8 as the template, an isostructural 
polymer of ZIF-67 with $\mathrm{Zn}^{2+}$ as the metal node instead of $\mathrm{Co}^{2+}$, Ru nanoparticles was synthesized (Supplementary Fig. S7 and S8).

The electronic structure of $\mathrm{Ru}-\mathrm{Cl}-\mathrm{N}$ SAC was further investigated by $\mathrm{X}$-ray photoelectron spectroscopy (XPS). The survey XPS pattern of $\mathrm{Ru}-\mathrm{Cl}-\mathrm{N}$ SAC displays the presence of $\mathrm{Ru}, \mathrm{Cl}, \mathrm{N}$ and $\mathrm{C}$ (Supplementary Fig. S9). Compared to the XPS survey of Co NP/Ru-Cl-N (Supplementary Fig. S10), the absence of Co signal in $\mathrm{Ru}-\mathrm{Cl}-\mathrm{N} \mathrm{SAC}$ indicated the completely removing of $\mathrm{Co}$ NP by acid etching. The high-resolution spectrum of Ru $3 p_{3 / 2}$ for Ru-Cl-N SAC can be deconvoluted into two peaks at 462.2 and $464.5 \mathrm{eV}$, which could be ascribed to metallic Ru and oxidized Ru species ${ }^{57}$, respectively. Meanwhile the Ru $2 p_{1 / 2}$ peaks at 484.2 and $487.2 \mathrm{eV}$ were assigned to the same species. The single peak for $\mathrm{Cl} 2 \mathrm{p}$ spectrum was observed at $199.4 \mathrm{eV}$, corresponding to Ru-Cl bond ${ }^{49}$. Besides, the $\mathrm{N} 1 \mathrm{~s}$ spectrum can be deconvoluted into several characteristic peaks. The XPS peaks located at 398.4, 399.1, 400.7, 401.4 and $403.1 \mathrm{eV}$ could be ascribed to pyridinic N, Ru-N, graphitic N, oxidized $\mathrm{N}$ and adsorbed $\mathrm{N}$ species ${ }^{56}$, respectively. The XPS results further confirmed the coordination environment of Ru that bonded with $\mathrm{Cl}$ and $\mathrm{N}$.

Electrocatalytic Performance of Ru-Cl-N SAC. The multifunctional electrocatalytic performance of Ru$\mathrm{Cl}-\mathrm{N}$ SAC for HER, OER and ORR was evaluated. For comparison, $\mathrm{RuN}_{4} \mathrm{SAC}, \mathrm{NC}$ and commercial Pt/C or $\mathrm{IrO}_{2}$ were also tested as reference samples. To get the accurate potentials, the reference electrode was calibrated against RHE in $\mathrm{H}_{2}$-saturated $\mathrm{KOH}$ electrolyte (Supplementary Fig. S11 and S12) ${ }^{57}$. HER and OER measurements were performed in a standard three-electrode electrochemical workstation in $1 \mathrm{M} \mathrm{N}_{2}{ }^{-}$ saturated $\mathrm{KOH}$ solution. As shown in Fig. 3a, the overall HER activity of $\mathrm{Ru}-\mathrm{Cl}-\mathrm{N} \mathrm{SAC}$ surpassed all the samples. The overpotential $\left(\eta_{10}\right)$ to reach a current density of $10 \mathrm{~mA} \mathrm{~cm}^{-2}$, which represents the reasonable descriptor of the catalytic activity ${ }^{58}$, was merely $12 \mathrm{mV}$ for $\mathrm{Ru}-\mathrm{Cl}-\mathrm{N} \mathrm{SAC}$, much lower than that of Pt/C (29 mV), RuN 4 SAC (131 mV) and NC (248 mV). The reaction kinetics was reflected by the Tafel plot, which was derived from the linear scan voltammetry (LSV) curve $^{8}$. The Tafel slope of $\mathrm{Ru}-\mathrm{Cl}-\mathrm{N}$ SAC (Fig. 3b) was fitted to be $23.9 \mathrm{mV} \mathrm{dec}^{-1}$, indicative a fast Volmer-Tafel pathway ${ }^{24}$. While the larger Tafel slope for Pt/C (47.8 $\left.\mathrm{mV} \mathrm{dec}^{-1}\right), \mathrm{RuN}_{4}$ SAC $\left(130.5 \mathrm{mV} \mathrm{dec}^{-1}\right)$ and NC $\left(287.9 \mathrm{mV} \mathrm{dec}^{-1}\right)$ revealed a sluggish Volmer-Heyrovsky route. Moreover, the turnover frequency (TOF) was estimated to evaluate the inherent electrocatalytic efficiency by means of underpotential deposition (UPD) of copper (Supplementary Fig. S13) ${ }^{38,59}$. The calculated TOF for Ru-Cl-N SAC was $0.66 \mathrm{H}_{2} \mathrm{~s}^{-1}$ at overpotential of $25 \mathrm{mV}$, which was two times larger than that of $\mathrm{Pt} / \mathrm{C}\left(0.32 \mathrm{H}_{2} \mathrm{~s}^{-1}\right)$, and comparable to many recentlyreported HER catalysts (Supplementary Fig. S14 and Table S2). The charge transfer kinetics was evaluated by the electrochemical impedance spectrum (EIS) measurement. From the Nyquist plot displayed in Fig. 3c, the charge transfer resistance $\left(R_{c t}\right)$ value was recorded as 8.72, 22.79, 26.90 and $197.3 \Omega$ for $\mathrm{Ru}-\mathrm{Cl}-\mathrm{N}$ SAC, Pt/C, $\mathrm{RuN}_{4}$ SAC and NC, respectively, demonstrating that $\mathrm{Ru}-\mathrm{Cl}-\mathrm{N}$ SAC underwent favorable charge transfer process during the HER reaction ${ }^{60}$. To investigate the intrinsic activity of the as-synthesized catalyst, double-layer capacitance $\left(\mathrm{C}_{\mathrm{dl}}\right)$ was obtained by cycling voltammetry (CV) measurement (Supplementary Fig. S15), which was proportional to the electrochemical 
active surface area (ECSA). ${ }^{8}$ The results showed that Ru-Cl-N SAC possessed the largest $\mathrm{C}_{\mathrm{dl}}(\mathrm{Fig} .3 \mathrm{~d})$, unveiling more active reaction sites in $\mathrm{Ru}-\mathrm{Cl}-\mathrm{N} \mathrm{SAC}$. It should be noted that the HER performance of Ru$\mathrm{Cl}-\mathrm{N} \mathrm{SAC}$ was superior to the benchmark Pt/C, and even better than many other recently-reported $\mathrm{Ru}$ based HER catalysts (Supplementary Table S3). Furthermore, the Ru-Cl-N SAC exhibited dramatical stability. From the long-term current-time curve (Fig. 3e), the activity of $\mathrm{Ru}-\mathrm{Cl}-\mathrm{N} \mathrm{SAC}$ could maintain stable for at least $120 \mathrm{~h}$.

The OER activity of Ru-Cl-N SAC was then carried out in the same condition. From the LSV curves depicted in Fig. $3 f$, the $\eta_{10}$ value for $\mathrm{Ru}-\mathrm{Cl}-\mathrm{N} \mathrm{SAC}\left(233 \mathrm{mV}\right.$ ) was much lower than that of $\mathrm{RuN}_{4} \mathrm{SAC}(362$ $\mathrm{mV}$ ) and $\mathrm{IrO}_{2}(347 \mathrm{mV})$. The corresponding Tafel slope of $\mathrm{Ru}-\mathrm{Cl}-\mathrm{N} \mathrm{SAC}$ disclosed a favorable reaction kinetics compared to other reference samples (Supplementary Fig. S16). Besides, the TOF was estimated to be $0.271 \mathrm{O}_{2} \mathrm{~s}^{-1}$ at overpotential of $300 \mathrm{mV}$, which is very competitive compared to many other reported OER catalysts (Supplementary Fig. S17 and Table S4). Furthermore, the $\mathrm{R}_{\mathrm{ct}}$ value (Supplementary Fig. S18) for Ru-Cl-N SAC (21.68 $\Omega$ ) measured at $10 \mathrm{~mA} \mathrm{~cm}{ }^{-2}$ disclosed a faster electron transfer process, compared to $\mathrm{RuN}_{4} \mathrm{SAC}(129.8 \Omega), \operatorname{IrO}_{2}(37.37 \Omega)$ and $\mathrm{NC}(245.2 \Omega)$. The intrinsic activity was then evaluated by $\mathrm{C}_{\mathrm{dl}}$ (Supplementary Fig. S19). The largest $\mathrm{C}_{\mathrm{dl}}$ value of $\mathrm{Ru}-\mathrm{Cl}-\mathrm{N} \mathrm{SAC}$ among all the tested samples demonstrated the atomically dispersion of $\mathrm{Ru}-\mathrm{Cl}-\mathrm{N} \mathrm{SAC}$ boosts more active reaction sites. The above results proved that the OER activity of $\mathrm{Ru}-\mathrm{Cl}-\mathrm{N} \mathrm{SAC}$ outperformed the commercial $\mathrm{IrO}_{2}$ and most reported Ru-based electrocatalysts in alkaline medium (Supplementary Table S5). The stability test suggested the $\mathrm{Ru}-\mathrm{Cl}-\mathrm{N} \mathrm{SAC}$ could endure the long-term chronoamperometry for more than $120 \mathrm{~h}$ (Fig. 3e).

The ORR performance of $\mathrm{Ru}-\mathrm{Cl}-\mathrm{N}$ SAC was characterized by rotating ring-disk electrode (RRDE) method in $0.1 \mathrm{M} \mathrm{KOH}$. Supplementary Fig. S20 compared the CV curves of $\mathrm{Ru}-\mathrm{Cl}-\mathrm{N} \mathrm{SAC}$ operated in $\mathrm{O}_{2}-$ saturated and Ar-saturated solution, displaying distinct ORR cathodic peak and demonstrating the occurrence of oxygen electroreduction at the electrode interface ${ }^{61}$. Fig. $3 \mathrm{~g}$ displayed the ORR polarized curves of all the catalysts with a rotating speed of $1600 \mathrm{rpm}$. Apparently, the Ru-Cl-N SAC exhibited remarkable ORR activity with the highest onset potential $\left(E_{\text {onset }}=1.10 \mathrm{~V}\right)$, strongest limited current density $\left(\mathrm{j}_{\mathrm{L}}=6.93 \mathrm{~mA} \mathrm{~cm}^{-2}\right)$ and largest half-wave potential $\left(\mathrm{E}_{1 / 2}=0.90 \mathrm{~V}\right)$. Notably, the $\mathrm{E}_{1 / 2}$ of $\mathrm{Ru}-\mathrm{Cl}-\mathrm{N}$ SAC was $70 \mathrm{mV}$ larger than that of the benchmark Pt/C catalyst, which was comparable or even better than many other reported ORR catalysts (Supplementary Table S6). Furthermore, the Tafel slope of Ru$\mathrm{Cl}-\mathrm{N}$ SAC was also smaller than other reference samples (Supplementary Fig. S21). The calculated number of electrons transferred per $\mathrm{O}_{2}$ molecule on the $\mathrm{Ru}-\mathrm{Cl}-\mathrm{N} \mathrm{SAC}$ electrode was close to 4.0

(Supplementary Fig. S22), indicating the ORR process followed the most efficient electron pathway ${ }^{62}$. The $\mathrm{H}_{2} \mathrm{O}_{2}$ generation yield was recorded lower than $1.9 \%$, confirming the high efficiency and selectivity of Ru$\mathrm{Cl}-\mathrm{N} \mathrm{SAC}$ toward ORR. The stability measurement disclosed that the $\mathrm{Ru}-\mathrm{Cl}-\mathrm{N} \mathrm{SAC}$ could continuously work for at least $20 \mathrm{~h}$ without apparent decay (Fig. 3h), much superior to the commercial Pt/C. Moreover, the $\mathrm{Ru}-\mathrm{Cl}-\mathrm{N}$ SAC exhibited robust tolerance of poisoning by methanol. Taking overall consideration of the performance of the present $\mathrm{Ru}-\mathrm{Cl}-\mathrm{N}$ SAC for HER, OER and ORR, this newly-synthesized 
multifunctional catalyst exhibited outstanding activities with favorable $\eta_{10}$ value (for HER and OER) and $\mathrm{E}_{1 / 2}$ (for ORR) among most recently-reported trifunctional electrocatalysts as shown in Fig. $3 \mathrm{i}$ and Supplementary Table S7.

Theoretical analysis of electrocatalytic mechanism for $\mathrm{Ru}-\mathrm{Cl}-\mathrm{N}$ SAC. To unveil the intrinsic active species for the newly-synthesized catalyst of $\mathrm{Ru}-\mathrm{Cl}-\mathrm{N} \mathrm{SAC}$, control experiments as well as DFT calculations were further performed. Firstly, LSV curves of Co NP/Ru-Cl-N SAC displayed slightly inferior catalytic activities for HER, OER and ORR compared with Ru-Cl-N SAC (Supplementary Fig. S23). DFT calculation indicated that the formation energy of $\mathrm{O}_{2}$ molecule on the (002) crystal surface of Co (Supplementary Fig. S24-S26) is too high and thus the OER process is indeed difficult due to the large overpotential $(4.86 \mathrm{eV})$. On the other hand, the adsorption free energy of $\mathrm{H}$ on the $\mathrm{Co}(002)$ plane is unfavorable for HER process (Supplementary Fig. S27). Therefore, Co NP was unable to promote the electrocatalytic reaction and deserved to be removed. Secondly, to uncover the role of the residue Ru NP within $\mathrm{Ru}-\mathrm{Cl}-\mathrm{N}$ SAC, KSCN and EDTA were used as poisoning agents to discover the contribution of Ru NP and single atomic Ru to the electrocatalytic reaction. It has been established that EDTA mainly coordinates with single atomic $\mathrm{Ru}$, while KSCN could cover both Ru NP and single atom ${ }^{24}$. The polarized curves (Supplementary Fig. S28) displayed similar poisoning effect of EDTA and KSCN for Ru-Cl-N SAC, elucidating that the single atom Ru species was the real intrinsic active sites.

To clearly show the effect of the coordination atom on the electrocatalytic activity, the $\mathrm{RuCl}_{2} \mathrm{~N}_{2} / \mathrm{C}$ configuration of a single Ru atom bonding with two $\mathrm{Cl}$ atoms and two $\mathrm{N}$ atoms in the carbon substrate was constructed, according to the XAFS and TEM results, to simulate the catalytic reactions of HER, OER and ORR. Moreover, a RuN $\mathrm{N}_{4} / \mathrm{C}$ model comprising a single $\mathrm{Ru}$ atom bonded with four $\mathrm{N}$ atoms was built for comparative analysis (Fig. 4a, b). The Hirshfeld charge partitioning analysis revealed that the introduction of the $\mathrm{Cl}$ atom effectively improves the catalytic activity of $\mathrm{Ru}^{62}$. The amount of charge transfer is about $0.35 \mathrm{e}$ (e is the unit of positive charge) from $\mathrm{Cl}$ to Ru atom (Fig. $4 \mathrm{c}$ and S29). To gain a deeper insight into the interaction of electronic structure, Fig. $4 \mathrm{~d}$ presents the partial density of states (PDOS) of $\mathrm{RuCl}_{2} \mathrm{~N}_{2} / \mathrm{C}$ and $\mathrm{RuN}_{4} / \mathrm{C}^{56}$. The large overlap between the Ru 3d states and $\mathrm{Cl} 2 \mathrm{p}$ states at the energy range from -4.5 to $2.0 \mathrm{eV}$ confirmed the strong interaction between $\mathrm{Cl}$ and $\mathrm{Ru}$ atom. Compared with the Ru 3d state peak of $\mathrm{RuN}_{4} / \mathrm{C}$, the Ru 3d state peak of $\mathrm{RuCl}_{2} \mathrm{~N}_{2} / \mathrm{C}$ near the Fermi level splits a part to above the Fermi level, so that Ru is more conducive to transfer of electrons to promote the catalytic reaction. The HER activity on $\mathrm{RuCl}_{2} \mathrm{~N}_{2} / \mathrm{C}$ and $\mathrm{RuN}_{4} / \mathrm{C}$ at different sites was also calculated as shown in Fig. 4e. The optimal value of $\Delta \mathrm{G}_{\mathrm{H}^{*}}$ is zero, which balances the adsorption and desorption capacity and represents high catalytic activity ${ }^{8}$. The most stable free energy of $\mathrm{H}$ adsorption is $0.10 \mathrm{eV}$ on $\mathrm{RuCl}_{2} \mathrm{~N}_{2} / \mathrm{C}$ and $-0.80 \mathrm{eV}$ on $\mathrm{RuN}_{4} / \mathrm{C}$, respectively. The optimal adsorption sites of the oxidized intermediates were tested on the $\mathrm{RuCl}_{2} \mathrm{~N}_{2} / \mathrm{C}$ and $\mathrm{RuN}_{4} / \mathrm{C}$ systems. The results showed that oxygencontaining intermediates tend to be adsorbed on Ru sites, indicating that Ru is the active site. The adsorption free energies of oxygen-containing species uncovered the origin of catalytic activities ${ }^{50}$. The OER and ORR catalytic performance on $\mathrm{RuCl}_{2} \mathrm{~N}_{2} / \mathrm{C}$ and $\mathrm{RuN}_{4} / \mathrm{C}$ was then evaluated by the change in free 
energies of each reaction step. It can be seen from Fig. $4 \mathrm{f}$ that $\mathrm{RuCl}_{2} \mathrm{~N}_{2} / \mathrm{C}$ and $\mathrm{RuN}_{4} / \mathrm{C}$ have the same rate-limiting steps. Due to the change of the coordination environment from $\mathrm{N}$ to $\mathrm{Cl}$ atom, the overpotentials of OER and ORR are reduced from 1.74 and $1.78 \mathrm{~V}$ to 1.07 and $1.06 \mathrm{~V}$, respectively. In addition, the overpotentials of OER and ORR are basically the same on $\mathrm{RuCl}_{2} \mathrm{~N}_{2} / \mathrm{C}(1.07 \mathrm{~V}$ vs. $1.06 \mathrm{~V})$, which indicated that $\mathrm{RuCl}_{2} \mathrm{~N}_{2} / \mathrm{C}$ has more potential as a dual-function catalyst for OER and ORR. On the whole, the DFT calculation results indicated that the catalytic activities for HER, OER and ORR on $\mathrm{RuCl}_{2} \mathrm{~N}_{2} / \mathrm{C}$ are favorable than those on $\mathrm{RuN}_{4} / \mathrm{C}$. The present work validated the pivotal role of $\mathrm{Cl}$ atom within $\mathrm{Ru}-\mathrm{Cl}-\mathrm{N} \mathrm{SAC}$ in boosting the electrocatalytic activity.

Overall water splitting and Zn-air battery. Inspired by the outstanding HER and OER activities of $\mathrm{Ru}-\mathrm{Cl}-\mathrm{N}$ SAC, the overall water splitting performance was further investigated ${ }^{8,50}$. As shown in Fig.5a, the homemade alkaline electrolyzer with two electrode construction was fabricated by using $\mathrm{Ru}-\mathrm{Cl}-\mathrm{N} \mathrm{SAC}$ supported on hydrophilic carbon paper both as cathode and anode. The Ru-Cl-N SAC $\mathbb{R u}-\mathrm{Cl}-\mathrm{N}$ SAC cell only required a voltage of $1.49 \mathrm{~V}$ to deliver a current density of $10 \mathrm{~mA} \mathrm{~cm}{ }^{-2}$, much lower than the cells $\left(1.59 \mathrm{~V}\right.$ ) assembled by commercial Pt/C and $\mathrm{IrO}_{2}$ (Fig. 5b), which is also superior to many recentlyreported bifunctional electrocatalysts (Supplementary Table S8). The chronoamperometry measurement disclosed that the Ru-Cl-N SAC $\triangle \mathrm{Ru}-\mathrm{Cl}-\mathrm{N}$ SAC cell could keep stable at $10 \mathrm{~mA} \mathrm{~cm}{ }^{-2}$ for at least $100 \mathrm{~h}$ without obvious degradation (inset of Fig. $5 \mathrm{~b}$ ) and numerous gaseous bubbles could be observed on both electrodes (Supplementary Fig. S30).

Benefiting from the excellent ORR and OER behavior of $\mathrm{Ru}-\mathrm{Cl}-\mathrm{N}$ SAC with low potential difference $(\triangle \mathrm{E}=$ $\mathrm{E}_{1 / 2}-\mathrm{E}_{\mathrm{OER} 10}$ ) of $0.56 \mathrm{~V}$, a rechargeable liquid $\mathrm{Zn}$-air battery was assembled by using $\mathrm{Ru}-\mathrm{Cl}-\mathrm{N} \mathrm{SAC}$ as cathode in $6 \mathrm{M} \mathrm{KOH}$ solution containing $0.2 \mathrm{M}$ zinc acetate (Fig.5c) $)^{4,62}$, and the mixture of Pt/C and $\mathrm{IrO}_{2}$ with a mass ratio of 1:1 was also tested for comparison. Supplementary Fig. S31 revealed that the Ru$\mathrm{Cl}-\mathrm{N}$ SAC-based battery possessed a stable open-circuit voltage (OCV) of $1.455 \mathrm{~V}$, slightly higher than that of $\mathrm{Pt} / \mathrm{C}-\mathrm{IrO}_{2}$ counterpart $(1.452 \mathrm{~V})$. Furthermore, the battery assembled by $\mathrm{Ru}-\mathrm{Cl}-\mathrm{N} \mathrm{SAC}$ delivered a maximum power density of $205 \mathrm{~mW} \mathrm{~cm}^{-2}$ at $325 \mathrm{~mA} \mathrm{~cm}^{-2}$ (Fig. 5d), much higher than that of $\mathrm{Pt} / \mathrm{C}-\mathrm{IrO}_{2}$ equipped battery $\left(87 \mathrm{~mW} \mathrm{~cm}^{-2}\right.$ at $\left.437 \mathrm{~mA} \mathrm{~cm}^{-2}\right)$. Besides, the specific capacity of Ru-Cl-N SAC-based battery hold a value of $804.26 \mathrm{mAh} \mathrm{g}^{-1}$, corresponding to a gravimetric energy density of $981.20 \mathrm{Wh} \mathrm{kg}^{-1}$ at $20 \mathrm{~mA} \mathrm{~cm}^{-2}$ (Fig. 5e), which is much better than those of $\mathrm{Pt} / \mathrm{C}^{-} \mathrm{IrO}_{2}$ equipped battery $\left(736.61 \mathrm{mAh} \mathrm{g}^{-1}\right.$ and $832.37 \mathrm{Wh} \mathrm{kg}^{-1}$ ) and comparable to many other reported $\mathrm{Zn}$-air batteries (Supplementary Table S9). An LED light array could be continuously lit by single Ru-Cl-N SAC-assembled battery for more than 20 h without brightness decay (Fig. $5 f$ and Supplementary Video S1). The cycling stability of the air cathode was then evaluated as displayed in Fig. $5 \mathrm{~g}$. Unlike $\mathrm{Pt} / \mathrm{C}-\mathrm{IrO}_{2}$ pair, where dramatical voltage degradation occurred after tens of cycles, tiny voltage decay was observed in $\mathrm{Ru}-\mathrm{Cl}-\mathrm{N} \mathrm{SAC}$-assembled battery after 1080 cycles $(360 \mathrm{~h})$ with a round-trip efficiency of $64 \%$, indicating the robust durability of $\mathrm{Ru}-\mathrm{Cl}-\mathrm{N} \mathrm{SAC}$. In addition, the multifunctional performance of $\mathrm{Ru}-\mathrm{Cl}-\mathrm{N} \mathrm{SAC}$ enabled the integration of $\mathrm{Zn}$-air battery and overall water electrolyzer cell. As displayed in Fig. 5h and Supplementary Video S2, a water splitting 
cell could be powered by two $\mathrm{Zn}$-air batteries in series fabricated by using $\mathrm{Ru}-\mathrm{Cl}-\mathrm{N} \mathrm{SAC}$ as the "all-inone" catalytic active material.

\section{Discussion}

In summary, a novel and efficient ruthenium single atom electrocatalyst coordinated with $\mathrm{Cl}$ and $\mathrm{N}(\mathrm{Ru}-$ $\mathrm{Cl}-\mathrm{N}$ ) was synthesized for the first time. X-ray synchrotron radiation adsorption spectrum combined with DFT calculation results unveiled an optimized coordination configuration of $\mathrm{RuCl}_{2} \mathrm{~N}_{2}$. The as-synthesized $\mathrm{Ru}-\mathrm{Cl}-\mathrm{N}$ SAC exhibited remarkable electrocatalytic activities toward HER, OER and ORR with low overpotential and long-term durability. In practice, a well-qualified assembly of overall water splitting cell and a rechargeable $\mathrm{Zn}$-air battery was fabricated using the $\mathrm{Ru}-\mathrm{Cl}-\mathrm{N} \mathrm{SAC}$ as the "all-in-one" active electrocatalytic material. The present work provided a new platform to design and fabricate novel and efficient multifunctional electrocatalyst for energy conversion and storage.

\section{Methods}

Synthesis of Ru-Cl-N SAC. $9 \mathrm{mmol}(2.619 \mathrm{~g})$ of $\mathrm{Co}\left(\mathrm{NO}_{3}\right)_{2} \cdot 6 \mathrm{H}_{2} \mathrm{O}$ and $1 \mathrm{mmol}(0.207 \mathrm{~g})$ of $\mathrm{RuCl}_{3}$ were dissolved in $30 \mathrm{~mL}$ of methanol under sonication to form solution $\mathrm{A}$, and $40 \mathrm{mmol}(3.284 \mathrm{~g})$ of 2methylimidazole (2-MIM) was dissolved in another $30 \mathrm{~mL}$ of methanol to form solution $\mathrm{B}$. Then solution $B$ was added into solution A slowly under sonication for $10 \mathrm{~min}$. The mixture was transfered to a Teflonlined autoclave capped with a stainless steel vessel. After heating at $160^{\circ} \mathrm{C}$ for $6 \mathrm{~h}$, the precipate was seperated by suction filtration, and washed with methanol several times before drying at $60{ }^{\circ} \mathrm{C}$ for $24 \mathrm{~h}$. The as-obtained purple powder precursor was defined as CoRu-ZIF-67. Afterwards, $200 \mathrm{mg}$ of CoRu-ZIF67 was placed in a crucible and heated at $700{ }^{\circ} \mathrm{C}$ for $2 \mathrm{~h}$ with a rate of $2{ }^{\circ} \mathrm{C} / \mathrm{min}$ under Ar atmosphere in a tube furnace. When the temperature decreased to $300{ }^{\circ} \mathrm{C}$ with a rate of $10{ }^{\circ} \mathrm{C} / \mathrm{min}$, it was cooled to room temperature naturally. The thus-obtained black powder, named as $\mathrm{Co} N \mathrm{NPu}-\mathrm{Cl}-\mathrm{N} \mathrm{SAC}$, was then dispersed in $1 \mathrm{M}$ of $\mathrm{H}_{2} \mathrm{SO}_{4}$ and $\mathrm{HF}$ under vigorously stirring for $24 \mathrm{~h}$ to remove the Co nanoparticles and unstable Ru species. The final product was obtained by suction filtration, washing with ethanol and water each three times and drying at $60^{\circ} \mathrm{C}$ for $24 \mathrm{~h}$, which was defined as $\mathrm{Ru}-\mathrm{Cl}-\mathrm{N} \mathrm{SAC}$.

Electrochemical measurement. The HER and OER properties were performed on CHI660E electrochemical workstation using a standard three-electrode system with graphtic rod, saturated calomel electrode (SCE) and glass carbon electrode (GCE) as the counter electrode, reference electrode and working electrode, respectively. The working electrode was prepared as follow: firstly, the GCE ( $f=3 \mathrm{~mm})$ was polished by aluminum oxide powder with a size distribution of 1.0, 0.5 and $0.05 \mu \mathrm{m}$ in sequence. Then $10 \mathrm{mg}$ of the as-synthesized catalyst ( $5 \mathrm{mg}$ of $\mathrm{Pt} / \mathrm{C}$ or $\mathrm{IrO}_{2}$ ) powder was dispersed into the a mixture of $400 \mu \mathrm{L}$ of isopropanol (IPA) and $16 \mu \mathrm{L}$ of Nafion solution through ultrasonication for $1 \mathrm{~h}$. Afterwards, $4 \mu \mathrm{L}$ of the catalyst ink was dip-coated onto the surface of GCE dried at room temperature. Before the test, the SCE reference electrode was calibrated against the $\mathrm{RHE}$ in $\mathrm{H}_{2}$-saturated $1 \mathrm{M} \mathrm{KOH}$ with Pt plate as the working electrode and Pt wire as the counter electrode ${ }^{63}$. Thus, the potentials in this work can be obtained by the 
equation of $E(R H E)=E(S C E)+1.059$. The LSV curve was recorded in a $\mathrm{N}_{2}$-saturated $1 \mathrm{M} \mathrm{KOH}$ with a scan rate of $3 \mathrm{mV} \mathrm{s}^{-1}$. Tafel slope was obtained by plotting the LSV curve using the equation of $\eta=a+b \log j$, where $\eta$ refers to the overpotential, $b$ is the Tafel slope and a denotes the intercept. ${ }^{8}$ The EIS were performed under open circuit potentials for all materials and the frequency range from $0.1 \mathrm{~Hz}$ to $100 \mathrm{kHz}$ with an amplitude of $5 \mathrm{mV}$ were used to carry out the experiment. The impedance data were represented by the Nyquist curve. For the $\mathrm{C}_{\mathrm{dl}}$ data, $\mathrm{CV}$ curves were recorded in the non-Faradic region with scanning rate of $2,4,6,8,10$ and $12 \mathrm{mV} \mathrm{s}^{-1}$, and the $C_{\mathrm{dl}}$ can be obtained by plotting the current difference $(\Delta \mathrm{j})$ against the scanning rate. The overall water splitting was conducted on a two-electrode setup with a scan rate of $3 \mathrm{mV} \mathrm{s}^{-1}$ under $1 \mathrm{M} \mathrm{KOH}$. The catalyst ink was coated on the hydrophilic carbon paper with an area of $1 \times 2 \mathrm{~cm}^{2}$ and dried at room temperature. For comparison, a water electrolyzer cell of $\mathrm{IrO}_{2} \otimes \mathrm{Pt} / \mathrm{C}$ was also fabricated using $5 \mathrm{mg}$ of $\mathrm{IrO}_{2}$ and $5 \mathrm{mg}$ of $20 \% \mathrm{Pt} / \mathrm{C}$ as the cathode and anode, respectively. The ORR measurement was carried out on a RRDE electrode $(f=4 \mathrm{~mm})$ equipped with a Pine WaveDrive20 instrument using Pt wire and SCE as the counter electrode and reference electrode, respectively. $6 \mu \mathrm{L}$ of the catalyst ink was dipped onto the disk surface and dried naturally. To be accurate, the SCE was also calibrated against RHE in $\mathrm{H}_{2}$-saturated 0.1 M KOH with RRDE as the working electrode and Pt wire as the counter electrode ${ }^{63}$. Thus, the potentials herein can be obtained by the equation of $E(R H E)=E(S C E)+1.0037$. CV curves were recorded in $\mathrm{N}_{2}$ - and $\mathrm{O}_{2}$-saturated $0.1 \mathrm{M} \mathrm{KOH}$ solution with a scan rate of $50 \mathrm{mV} \mathrm{s}^{-1}$. LSV curves were performed under $\mathrm{O}_{2}$-saturated $0.1 \mathrm{M} \mathrm{KOH}$ solution with a scan rate of $1600 \mathrm{rpm}$. The hydrogen peroxide yield $\left(\mathrm{H}_{2} \mathrm{O}_{2} \%\right)$ and the electron transfer number $(n)$ were calculated from the current of both disk and ring electrodes using the following equation: ${ }^{30}$

$$
\begin{aligned}
& H_{2} O_{2} \%=200 \times \frac{I_{r}}{I_{r}+N I_{d}} \\
& n=4 \times \frac{I_{d}}{I_{d}+\frac{I_{r}}{N}}
\end{aligned}
$$

where $I_{r}$ is the ring current, $I_{d}$ is the disk current, and the current collection efficiency $(N)$ the of Pt ring is determined to be 0.38 in our system.

$\mathrm{Zn}$-air battery test. For the fabrication of the liquid rechargeable Zn-air battery, $18 \mathrm{mg}$ of catalyst and 2 mg of conductive carbon black were firstly dispersed into a mixture of $960 \mu \mathrm{L}$ of IPA and $40 \mu \mathrm{L}$ of Nafion solution under ultrasonication for $1 \mathrm{~h}$. Then, $50 \mu \mathrm{L}$ of the catalyst ink was dip-coated onto the surface of gas diffusion layer (GDL) $\left(1 \mathrm{~cm}^{2}\right)$ as the cathodic air electrode and a piece of Zn plate $\left(4.5 \mathrm{~cm}^{2}\right)$ was used as anodic electrode. The cell was conducted in $6 \mathrm{M} \mathrm{KOH}$ with $0.2 \mathrm{M}$ zinc acetate ${ }^{62}$. The discharge polarization curve was measured in the voltage range of 1.55 to $0.2 \mathrm{~V}$ with a scan rate of $5 \mathrm{mV} \mathrm{s}^{-1}$, and the specific capacity was tested under a current density of $20 \mathrm{~mA} \mathrm{~cm} \mathrm{~cm}^{-2}$. The charge-discharge cycling stability was acquired under $2 \mathrm{~mA} \mathrm{~cm}^{-2}$ with charge-discharge interval of $10 \mathrm{~min}$. For comparison, another 
reference cell assembly by a mixture catalyst of $5 \mathrm{mg} \mathrm{IrO}$ and $5 \mathrm{mg} 20 \% \mathrm{Pt} / \mathrm{C}$ as the air electrode in the similar preparation procedure.

Computational method. All the spin-unrestricted DFT calculations were carried out using the $\mathrm{Dmol}^{3}$ module in the Materials studio ${ }^{64}$. The exchange-correlation of the electron was performed by the generalized gradient approximation (GGA) ${ }^{65}$ method with Perdew-Burke-Ernzerhof (PBE) ${ }^{66}$. The van der Waals force is treated with long-range dispersion correction through Tkatchenko and Scheffler's scheme ${ }^{67}$. During geometric structural optimizations, the convergence criteria were set to $10^{-5} \mathrm{Ha}$ for the energy, $0.002 \mathrm{Ha} / \AA ̊$ for the force, and $0.005 \AA$ for the displacement. The smearing value was set to 0.005 $\mathrm{Ha}$ to achieve self-consistent field convergence. The change in Gibbs free energy $(\Delta \mathrm{G})$ for each reaction step is given by the equation of $\Delta \mathrm{G}=\Delta \mathrm{E}+\Delta \mathrm{E}_{\mathrm{ZPE}}-\mathrm{T} \Delta \mathrm{S}+\Delta \mathrm{G}_{\mathrm{U}}$, where $\Delta \mathrm{E}$ is the reaction energy gained from the DFT calculations, $\Delta \mathrm{E}_{\mathrm{ZPE}}$ is the change of zero-point energy, $\mathrm{T}$ is the temperature $(298.15 \mathrm{~K})$ and $\Delta S$ is the change of entropy. $\Delta G_{U}=-n e U$, in which $n$ is the number of transferred electrons and $U$ is the applied potential. The overpotential $(\square)$ can be calculated by the following equations of $\square(O E R)=$ $\Delta \mathrm{Gmax} / \mathrm{e}-1.23$, and $\otimes(\mathrm{ORR})=\Delta \mathrm{Gmax} / \mathrm{e}+1.23$.

\section{References}

1. Tiwari J. N. et al. Multicomponent electrocatalyst with ultralow Pt loading and high hydrogen evolution activity. Nat. Energy 3, 773-782 (2018).

2. Sun T. et al. Design of local atomic environments in single-atom electrocatalysts for renewable energy conversions. Adv. Mater. 33, 2003075 (2021).

3. Peng Y., Lu B., Chen S. Carbon-supported single atom catalysts for electrochemical energy conversion and storage. Adv. Mater. 30, 1801995 (2018).

4. Wei Y-S., Zhang M., Kitta M., Liu Z., Horike S., Xu Q. A single-crystal open-capsule metal-organic framework. J. Am. Chem. Soc. 141, 7906-7916 (2019).

5. Kuang P. Y., Sayed M., Fan J. J., Cheng B., Yu J. G. 3D graphene-based $\mathrm{H}_{2}$-production photocatalyst and electrocatalyst. Adv. Energy Mater. 10, 1903802 (2020).

6. Ahsan M. A. et al. Tuning of trifunctional NiCu bimetallic nanoparticles confined in a porous carbon network with surface composition and local structural distortions for the electrocatalytic oxygen reduction, oxygen and hydrogen evolution reactions. J. Am. Chem. Soc. 142, 14688-14701 (2020).

7. Feng Y. et al. Defect-rich bimetallic yolk-shell metal-cyanide frameworks as efficient electrocatalysts for oxygen evolution reactions. J. Mater. Chem. A 9, 2135-2144 (2021).

8. Pan Y. et al. Core-shell ZIF-8@ZIF-67-derived CoP nanoparticle-embedded N-doped carbon nanotube hollow polyhedron for efficient overall water splitting. J. Am. Chem. Soc. 140, 2610-2618 (2018).

9. Wang H., Yang Y., DiSalvo F. J., Abruña H. D. Multifunctional electrocatalysts: Ru-M ( $\mathrm{M}=\mathrm{Co}, \mathrm{Ni}, \mathrm{Fe})$ for alkaline fuel cells and electrolyzers. ACS Catal. 10, 4608-4616 (2020). 
10. Luo F. et al. Palladium phosphide as a stable and efficient electrocatalyst for overall water splitting. Angew. Chem. Int. Ed. 57, 14862-14867 (2018).

11. Anantharaj S. et al. Enhancing electrocatalytic total water splitting at few layer Pt-NiFe layered double hydroxide interfaces. Nano Energy 39, 30-43 (2017).

12. Zhu Y., Lin Q., Zhong Y., Tahini H. A., Shao Z., Wang H. Metal oxide-based materials as an emerging family of hydrogen evolution electrocatalysts. Energy Environ. Sci. 13, 3361-3392 (2020).

13. Li Y. H. et al. Local atomic structure modulations activate metal oxide as electrocatalyst for hydrogen evolution in acidic water. Nat. Commun. 6, 8064 (2015).

14. Wei C., Sun S., Mandler D., Wang X., Qiao S. Z., Xu Z. J. Approaches for measuring the surface areas of metal oxide electrocatalysts for determining their intrinsic electrocatalytic activity. Chem. Soc. Rev. 48, 2518-2534 (2019).

15. Tian X. et al. Transition metal nitride coated with atomic layers of Pt as a low-cost, highly stable electrocatalyst for the oxygen reduction reaction. J. Am. Chem. Soc. 138, 1575-1583 (2016).

16. Yu L. et al. Non-noble metal-nitride based electrocatalysts for high-performance alkaline seawater electrolysis. Nat. Commun. 10, 5106 (2019).

17. Dutta S., Indra A., Feng Y., Han H., Song T. Promoting electrocatalytic overall water splitting with nanohybrid of transition metal nitride-oxynitride. Appl. Catal. B-Environ. 241, 521-527 (2019).

18. Lian Y. et al. Carved nanoframes of cobalt-iron bimetal phosphide as a bifunctional electrocatalyst for efficient overall water splitting. Chem. Sci. 10, 464-474 (2019).

19. Chen D. et al. Ultralow Ru loading transition metal phosphides as high-efficient bifunctional electrocatalyst for a solar-to-hydrogen generation system. 10, 2000814 (2020).

20. Ma B., Yang Z., Chen Y., Yuan Z. Nickel cobalt phosphide with three-dimensional nanostructure as a highly efficient electrocatalyst for hydrogen evolution reaction in both acidic and alkaline electrolytes. Nano Res. 12, 375-380 (2019).

21. Greeley J. et al. Alloys of platinum and early transition metals as oxygen reduction electrocatalysts. Nat. Chem. 1, 552-556 (2009).

22. Liu H. et al. Free-standing nanoporous NiMnFeMo alloy: An efficient non-precious metal electrocatalyst for water splitting. Chem. Eng. J. 404, 126530 (2021).

23. Zhang F. et al. RuCo alloy bimodal nanoparticles embedded in N-doped carbon: A superior $\mathrm{pH}-$ universal electrocatalyst outperforms benchmark $\mathrm{Pt}$ for the hydrogen evolution reaction. J. Mater. Chem. A 8, 12810-12820 (2020).

24. Lu B. et al. Ruthenium atomically dispersed in carbon outperforms platinum toward hydrogen evolution in alkaline media. Nat. Commun. 10, 631 (2019).

25. Wang J. et al. Single atom Ru doping $2 \mathrm{H}-\mathrm{MoS}_{2}$ as highly efficient hydrogen evolution reaction electrocatalyst in a wide pH range. Appl. Catal. B-Environ. 298, 120490 (2021).

26. Zhang J., Xu X., Yang L., Cheng D., Cao D. Single-atom Ru doping induced phase transition of $\mathrm{MoS}_{2}$ and S vacancy for hydrogen evolution reaction. Small Methods 3, 1900653 (2019). 
27. Kumar N. et al. Multifunctionality exploration of $\mathrm{Ca}_{2} \mathrm{FeRuO}_{6}$ : An efficient trifunctional electrocatalyst toward OER/ORR/HER and photocatalyst for water splitting. ACS Appl. Energy Mater. 4, 1323-1334 (2021).

28. Xiao M. et al. Engineering energy level of metal center: Ru single-atom site for efficient and durable oxygen reduction catalysis. J. Am. Chem. Soc. 141, 19800-19806 (2019).

29. Cao L. et al. Dynamic oxygen adsorption on single-atomic ruthenium catalyst with high performance for acidic oxygen evolution reaction. Nat. Commun. 10, 4849 (2019).

30. Zhao L. et al. Cascade anchoring strategy for general mass production of high-loading single-atomic metal-nitrogen catalysts. Nat. Commun. 10, 1278 (2019).

31. Boyes E. D., LaGrow A. P., Ward M. R., Mitchell R. W., Gai P. L. Single atom dynamics in chemical reactions. Acc. Chem. Res. 53, 390-399 (2020).

32. Wang $X$. et al. Review of metal catalysts for oxygen reduction reaction: From nanoscale engineering to atomic design. Chem 5, 1486-1511 (2019).

33. Zhang L., Ren Y., Liu W., Wang A., Zhang T. Single-atom catalyst: a rising star for green synthesis of fine chemicals. Natl. Sci. Rev. 5, 653-672 (2018).

34. Yang L. et al. Unveiling the high-activity origin of single-atom iron catalysts for oxygen reduction reaction. P. Natl. Acad. Sci. USA 115, 6626-6631 (2018).

35. Cao D., Wang J., Xu H., Cheng D. Construction of dual-site atomically dispersed electrocatalysts with Ru- $\mathrm{C}_{5}$ single atoms and $\mathrm{Ru}-\mathrm{O}_{4}$ nanoclusters for accelerated alkali hydrogen evolution. Small 17, 2101163 (2021).

36. Zhao C. et al. Insights into the electronic origin of enhancing the catalytic activity of $\mathrm{Co}_{3} \mathrm{O}_{4}$ for oxygen evolution by single atom ruthenium. Nano Today 34, 100955 (2020).

37. Chen Y. et al. Enhanced oxygen reduction with single-atomic-site iron catalysts for a zinc-air battery and hydrogen-air fuel cell. Nat. Commun. 9, 5422 (2018).

38. Mahmood J. et al. An efficient and pH-universal ruthenium-based catalyst for the hydrogen evolution reaction. Nat. Nanotech. 12, 441-446 (2017).

39. Li Q. et al. Fe isolated single atoms on $\mathrm{S}, \mathrm{N}$ codoped carbon by copolymer pyrolysis strategy for highly efficient oxygen reduction reaction. Adv. Mater. 30, 1800588 (2018).

40. Wang J. et al. Turning on $\mathrm{Zn} 4 \mathrm{~s}$ electrons in a $\mathrm{N}_{2}-\mathrm{Zn}-\mathrm{B}_{2}$ configuration to stimulate remarkable ORR performance. Angew. Chem. Int. Ed. 60, 181-185 (2021).

41. Zhou S. et al. Ru atom-modified $\mathrm{Co}_{4} \mathrm{~N}-\mathrm{CoF}_{2}$ heterojunction catalyst for high-performance alkaline hydrogen evolution. Chem. Eng. J. 414, 128865 (2021).

42. Pai S. J., Han S. S. $S_{E} 2$ reaction in noncarbon system: Metal-halide catalysis for dehydrogenation of ammonia borane. P. Natl. Acad. Sci. USA 114, 13625-13630 (2017).

43. Qi H. et al. Highly selective and robust single-atom catalyst $\mathrm{Ru}_{1} / \mathrm{NC}$ for reductive amination of aldehydes/ketones. Nat. Commun. 12, 3295 (2021). 
44. Fagnou K., Lautens M. Halide effects in transition metal catalysis. Angew. Chem. Int. Ed. 41, 26-47 (2002).

45. Méndez-Galván M., Alcántar-Vázquez B., Diaz G., Ibarra I. A., Lara-García H. A. Metal halide perovskites as an emergent catalyst for $\mathrm{CO}_{2}$ photoreduction: a mini review. React. Chem. Eng. 6, 828-838 (2021).

46. Han C., Zhu X., Martin J. S., Lin Y., Spears S., Yan Y. Recent progress in engineering metal halide perovskites for efficient visible-light-driven photocatalysis. ChemSusChem 13, 4005-4025 (2020).

47. Bresolin B-M., Park Y., Bahnemann D. W. Recent progresses on metal halide perovskite-based material as potential photocatalyst. Catalysts 10, 709 (2020).

48. Kim M-S. et al. Copper-halide polymer nanowires as versatile supports for single-atom catalysts. Small 15, 1903197 (2019).

49. Wang W. et al. Oxide passivated CoNi@NC-supported $\mathrm{Ru}(\mathrm{OH})_{x} \mathrm{Cl}_{y}$ cluster as highly efficient catalysts for the oxygen and hydrogen evolution. ACS Sustain. Chem. Eng. 7, 17227-17236 (2019).

50. Feng Y. et al. Decorating CoNi layered double hydroxides nanosheet arrays with fullerene quantum dot anchored on $\mathrm{Ni}$ foam for efficient electrocatalytic water splitting and urea electrolysis. Chem. Eng. J. 390, 124525 (2020).

51. Tonda S., Kumar S., Kandula S., Shanker V. Fe-doped and -mediated graphitic carbon nitride nanosheets for enhanced photocatalytic performance under natural sunlight. J. Mater. Chem. A 2, 6772-6780 (2014).

52. Qin Q., Jang H., Li P., Yuan B., Liu X., Cho J. A tannic acid-derived N-, P-codoped carbon-supported iron-based nanocomposite as an advanced trifunctional electrocatalyst for the overall water splitting cells and zinc-air batteries. Adv. Energy Mater. 9, 1803312 (2019).

53. Wang Y. et al. Cytosine-Co assemblies derived $\mathrm{CoN}_{\mathrm{x}}$ rich Co-NCNT as efficient tri-functional electrocatalyst. J. Colloid Interf. Sci. 585, 276-286 (2021).

54. Xia C. et al. General synthesis of single-atom catalysts with high metal loading using graphene quantum dots. Nat. Chem., (2021).

55. Liu H. et al. Metal-organic-framework-derived $\mathrm{Co}_{2} \mathrm{P}$ nanoparticle/multi-doped porous carbon as a trifunctional electrocatalyst. Adv. Mater. 32, 2003649 (2020).

56. Hu X. et al. Ru single atoms on N-doped carbon by spatial confinement and ionic substitution strategies for high-performance $\mathrm{Li}-\mathrm{O}_{2}$ batteries. J. Am. Chem. Soc. 142, 16776-16786 (2020).

57. Su P. et al. Exceptional electrochemical HER performance with enhanced electron transfer between Ru nanoparticles and single atoms dispersed on a carbon substrate. Angew. Chem. Int. Ed. 60, 16044-16050 (2021).

58. Luo J. et al. Water photolysis at $12.3 \%$ efficiency via perovskite photovoltaics and Earth-abundant catalysts. Science 345, 1593-1596 (2014).

59. Kweon D. H. et al. Ruthenium anchored on carbon nanotube electrocatalyst for hydrogen production with enhanced Faradaic efficiency. Nat. Commun. 11, 1278 (2020). 
60. Liu J. et al. Visualizing spatial potential and charge distribution in Ru/N-doped carbon electrocatalysts for superior hydrogen evolution reaction. J. Mater. Chem. A 7, 18072-18080 (2019).

61. Barman B. K., Sarkar B., Nanda K. K. Pd-coated Ru nanocrystals supported on N-doped graphene as HER and ORR electrocatalysts. Chem. Commun. 55, 13928-13931 (2019).

62. Yan L. et al. A Freestanding 3D heterostructure film stitched by MOF-derived carbon nanotube microsphere superstructure and reduced graphene oxide sheets: A superior multifunctional electrode for overall water splitting and Zn-air batteries. Adv. Mater. 32, 2003313 (2020).

63. Wei C. et al. Recommended practices and benchmark activity for hydrogen and oxygen electrocatalysis in water splitting and fuel cells. Adv. Mater. 31, 1806296 (2019).

64. Delley B. From molecules to solids with the DMol ${ }^{3}$ approach. J. Chem. Phys. 113, 7756-7764 (2000).

65. Grimme S. Semiempirical GGA-type density functional constructed with a long-range dispersion correction. J. Comput. Chem. 27, 1787-1799 (2006).

66. Ernzerhof M., Scuseria G. E. Assessment of the Perdew-Burke-Ernzerhof exchange-correlation functional. J. Chem. Phys. 110, 5029-5036 (1999).

67. Tkatchenko A., Scheffler M. Accurate molecular Van Der Waals interactions from ground-state electron density and free-atom reference data. Phys. Rev. Lett. 102, 073005 (2009).

\section{Figures}



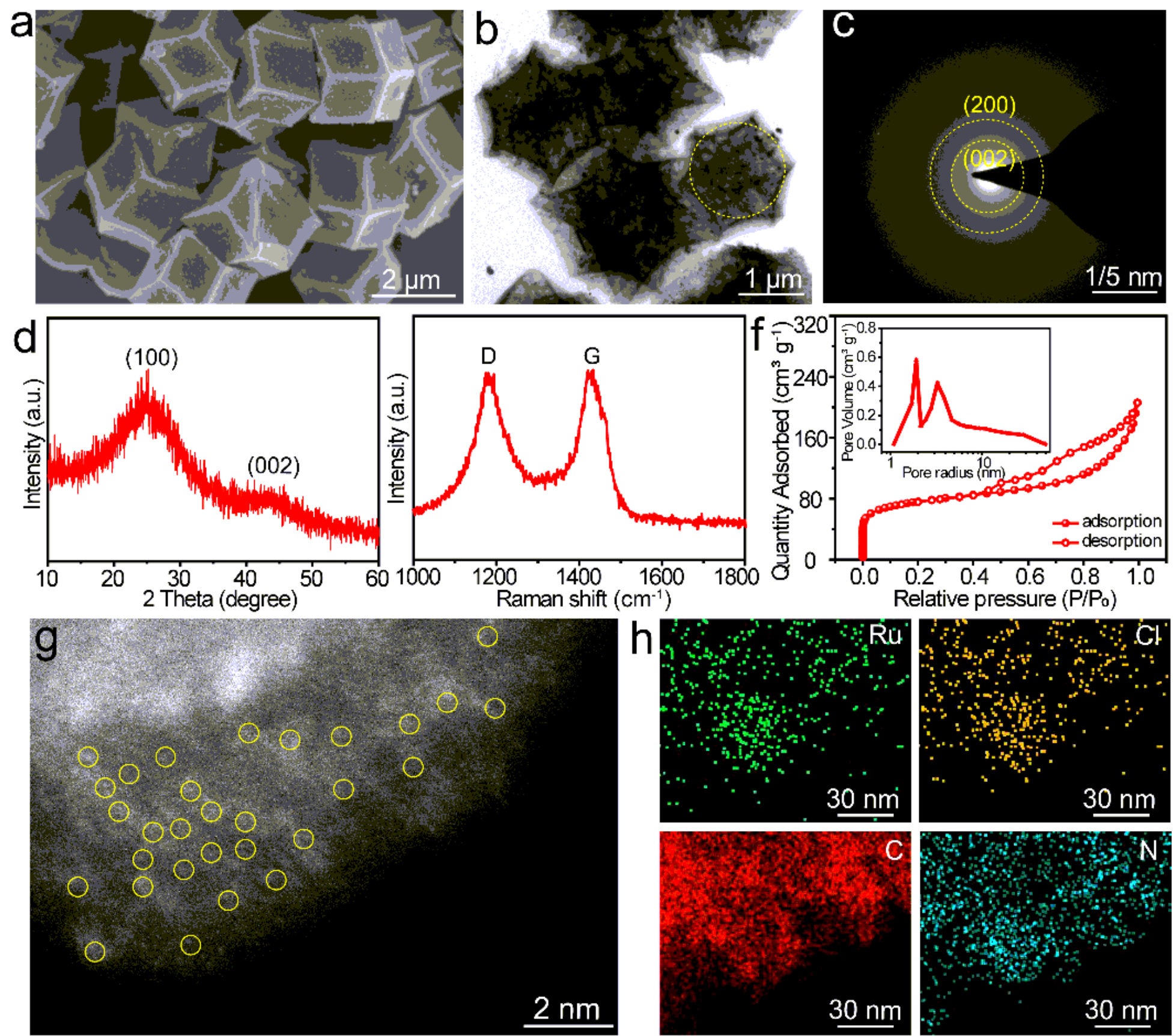

Figure 1

Morphology and structure characterization of Ru-Cl-N SAC. a SEM and b TEM images of $\mathrm{Ru}-\mathrm{Cl}-\mathrm{N}$ SAC. c SAED pattern for the particle marked in b. $d$ XRD pattern, e Raman spectrum, $f$ specific surface area of $\mathrm{Ru}-\mathrm{Cl}-\mathrm{N} \mathrm{SAC}$, inset of $f$ showing the pore volume distribution of $\mathrm{Ru}-\mathrm{Cl}-\mathrm{N}$ SAC. $g$ AC-HAADF-STEM images of $\mathrm{Ru}-\mathrm{Cl}-\mathrm{N} \mathrm{SAC}$, the yellow circles marked the single Ru atom guided for the eye. $\mathrm{h}$ Elemental mapping for Ru (green), $\mathrm{Cl}$ (orange), $\mathrm{C}$ (red) and $\mathrm{N}$ (cyan) of $\mathrm{Ru}-\mathrm{Cl}-\mathrm{N} \mathrm{SAC}$. 

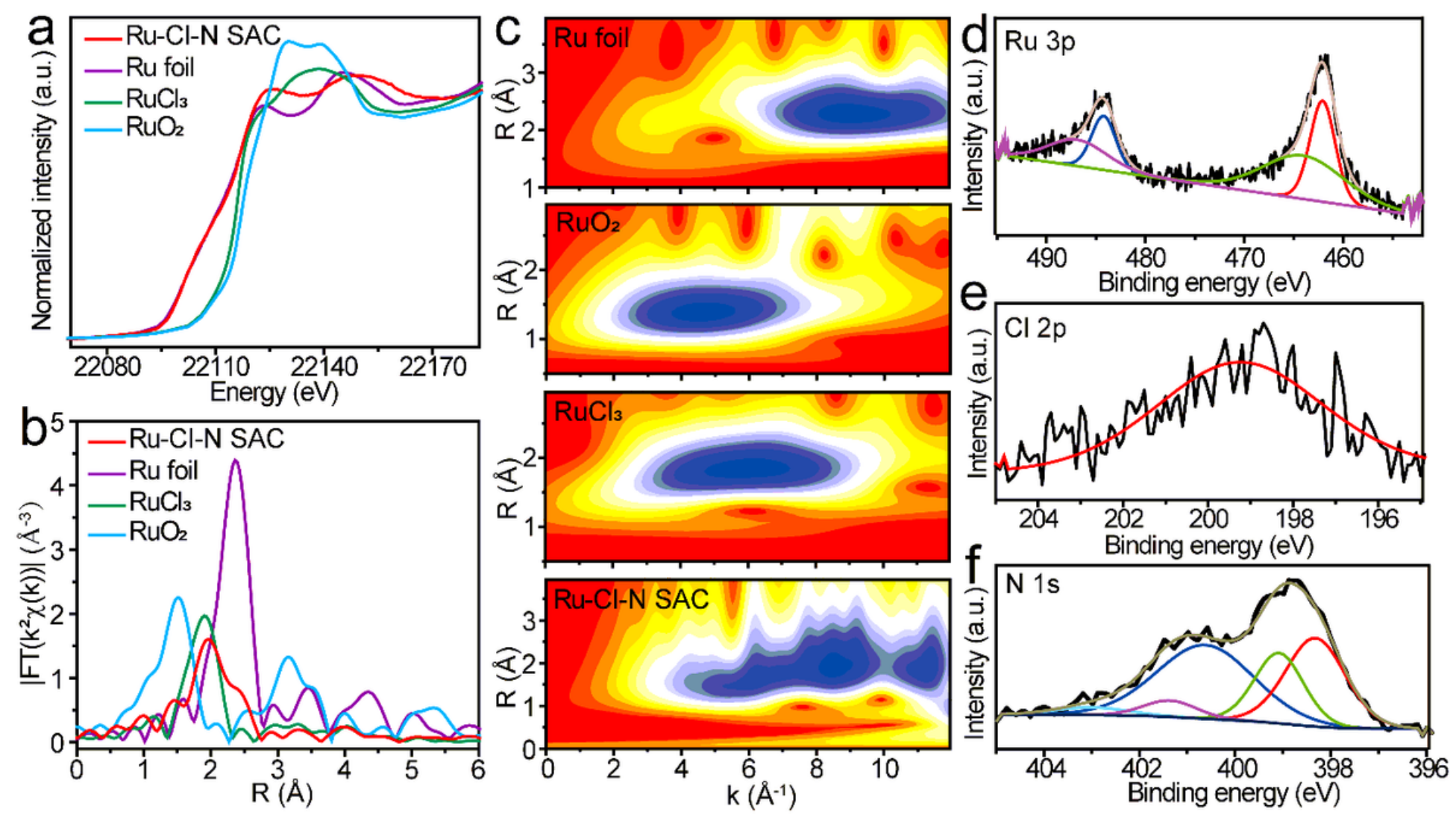

Figure 2

Atomic structure analysis of Ru-Cl-N SAC by XAFS and XPS. a Normalized Ru K-edge XANES spectra and b Fourier-transform of Ru K-edge EXAFS of Ru-Cl-N SAC (red), Ru foil (purple), RuCl3 (green) and RuO2 (blue). c Wavelet transform spectra of the EXAFS of Ru foil, RuO2, RuCl3, and Ru-Cl-N SAC. d-f High-resolution deconvoluted XPS spectra of Ru 3p, Cl 2p and N 1s of Ru-Cl-N SAC. 

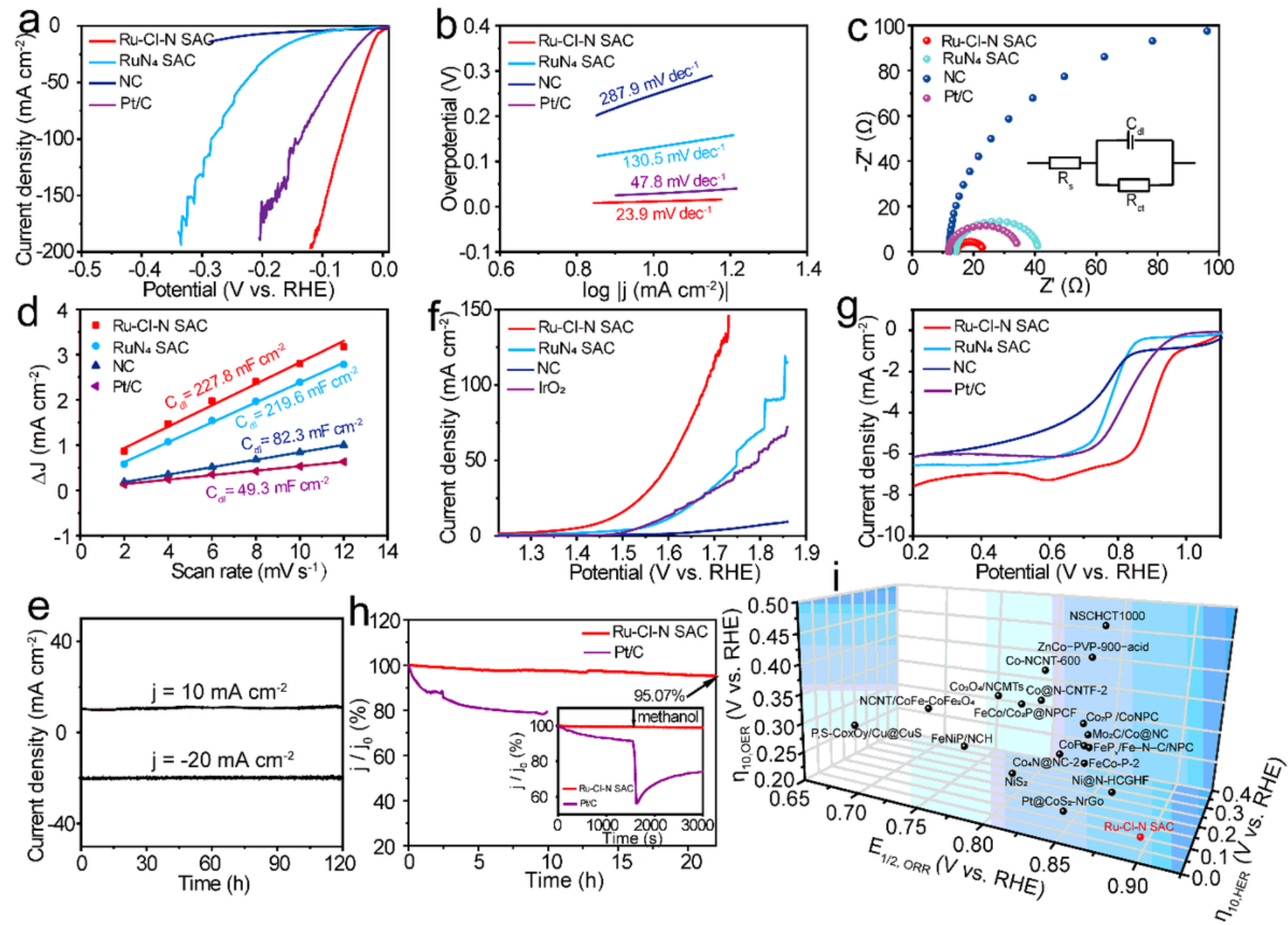

\section{Figure 3}

Electrochemical properties of Ru-Cl-N SAC. a LSV curves, b Tafel slope, c Nyquist plots, d current density difference against scan rate for HER process of Ru-Cl-N SAC (red), RuN4 SAC (cyan), NC (blue) and Pt/C (purple). e Chronoamperometric current-time curves for HER (bottom curve) and OER (top curve). $f$ LSV curves for the OER process and g ORR process of Ru-Cl-N SAC (red), RuN4 SAC (cyan), NC (blue) and Pt/C (purple). h Chronoamperometry study of Ru-Cl-N SAC (red) and Pt/C (purple), inset of h showing the methanol durability test of $\mathrm{Ru}-\mathrm{Cl}-\mathrm{N} \mathrm{SAC}$ (red) and Pt/C (purple). i comparison diagram of the overpotential for HER ( $\eta 10, \mathrm{HER}), \mathrm{OER}(\mathrm{\eta} 10, \mathrm{OER})$ and half-wave potential for ORR (E1/2, ORR) of Ru$\mathrm{Cl}-\mathrm{N}$ SAC with other recently-reported trifunctional electrocatalyst. 


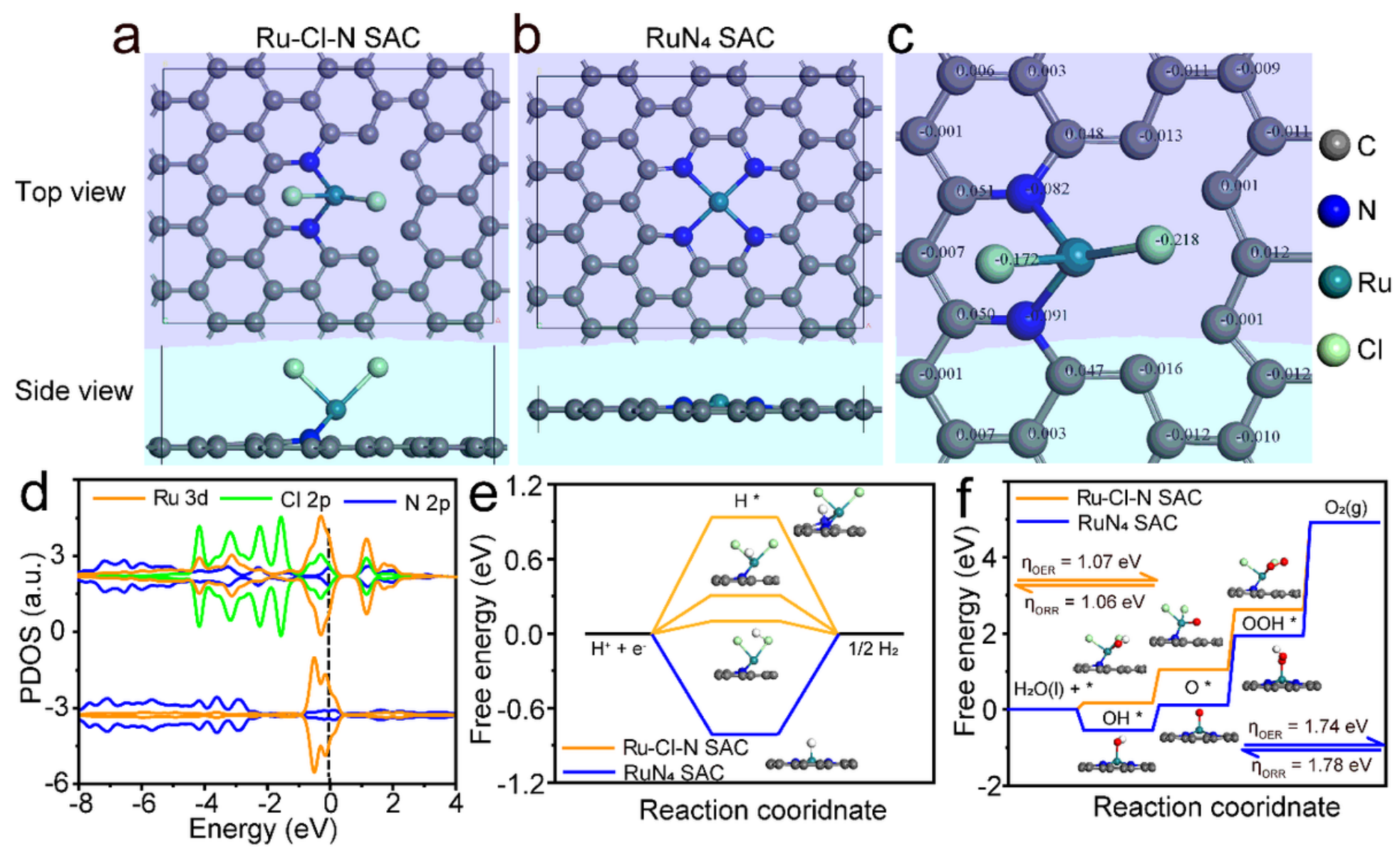

Figure 4

Theoretical analysis on the electronic structure and reaction mechanism of $\mathrm{Ru}-\mathrm{Cl}-\mathrm{N}$ SAC. a, b Top view and side view of the optimized structure of Ru-Cl-N SAC and RuN4 SAC. c Charge partitioning obtained by Hirshfeld method. Color code: $\mathrm{C}$ gray, $\mathrm{N}$ blue, Ru cyan, $\mathrm{Cl}$ green. $\mathrm{d}$ PDOS diagram of $\mathrm{Ru} 3 \mathrm{~d}$ (orange), $\mathrm{Cl}$ $2 p$ (green) and N 2p (blue) for Ru-Cl-N SAC (top panel) and RuN4 SAC (bottom panel). e Free energy diagram for Ru-Cl-N SAC (orange) and RuN4 SAC (blue) on the HER process. f Free energy diagram for $\mathrm{Ru}-\mathrm{Cl}-\mathrm{N}$ SAC (orange) and RuN4 SAC (blue) on the OER and ORR process. The structures in e, fillustrate the hydrogen- and oxygen-containing intermediates of the catalyst, the calculated overpotentials of OER and ORR are 1.07 and $1.06 \mathrm{~V}$, respectively for $\mathrm{Ru}-\mathrm{Cl}-\mathrm{N} \mathrm{SAC}$, and 1.74 and $1.78 \mathrm{~V}$ for RuN4 SAC. 
a

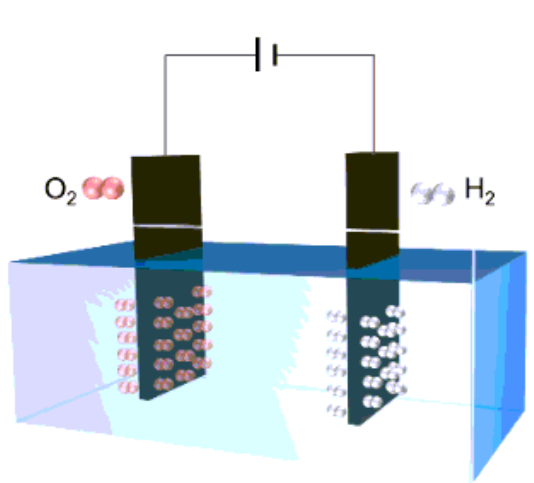

b

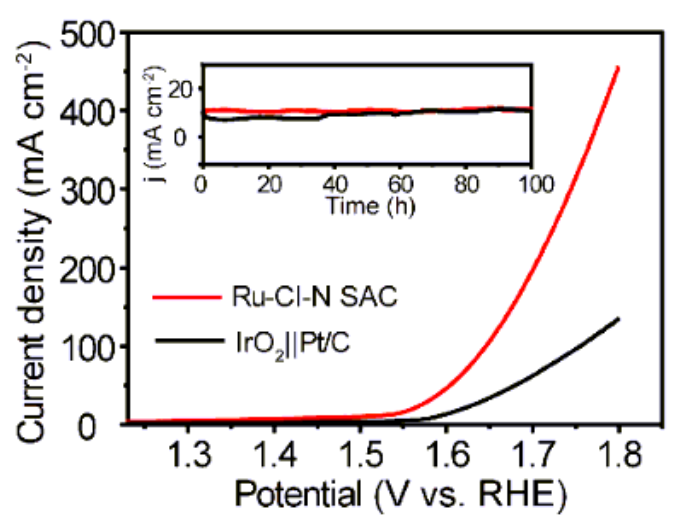

C

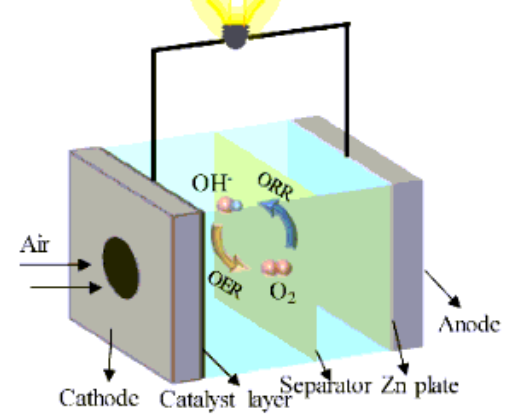

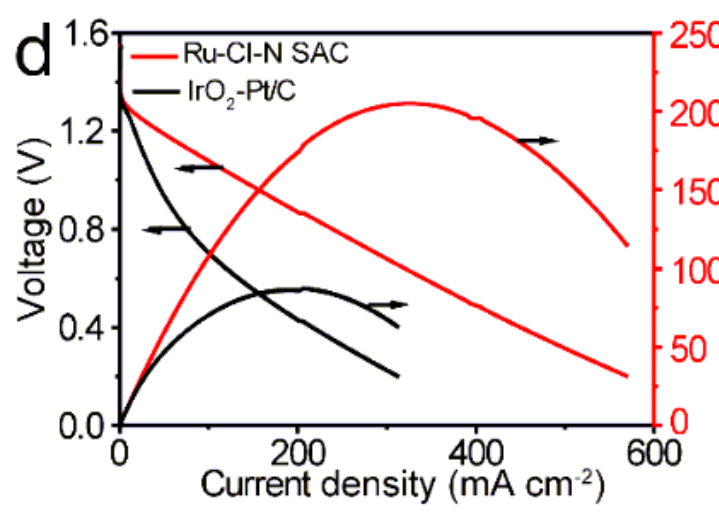
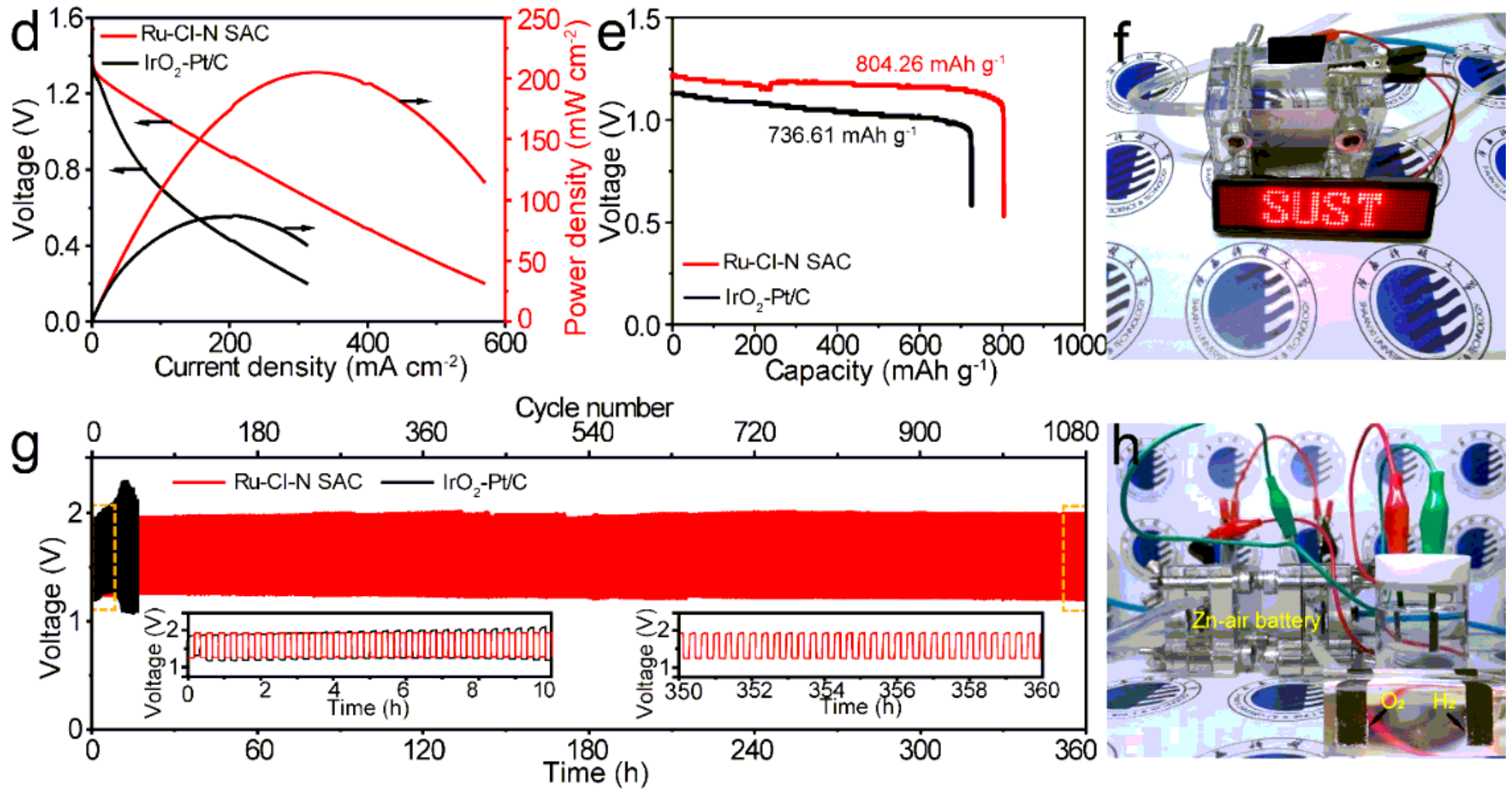

Figure 5

Overall water splitting and Zn-air battery performance of Ru-Cl-N SAC. a Schematic illustration of the overall water splitting electrolyzer cell. b LSV curves for the overall water splitting electrolyzer cell fabricated by $\mathrm{Ru}-\mathrm{Cl}-\mathrm{N} \mathrm{SAC}$ (red) and Pt/C-IrO2 (black). Inset of b showing the corresponding chronoamperometric current-time curves of $\mathrm{Ru}-\mathrm{Cl}-\mathrm{N} \mathrm{SAC}$ (red) and Pt/C-IrO2 (black) of the two cells in b. c Schematic illustration of the configuration of the homemade Zn-air battery. $d$ Discharging polarization curves and the corresponding power density plots of $\mathrm{Ru}-\mathrm{Cl}-\mathrm{N} \mathrm{SAC}$-based (red) and Pt/CIrO2-based (black) Zn-air battery. e Specific capacity curves of Ru-Cl-N SAC-based (red) and Pt/C-IrO2based (black) Zn-air battery. $\mathrm{f}$ Optical image of a LED display driven by a single $\mathrm{Ru}-\mathrm{Cl}-\mathrm{N} \mathrm{SAC}$-based Znair battery. $\mathrm{g}$ Charge-discharge cycling performance of $\mathrm{Ru}-\mathrm{Cl}-\mathrm{N} \mathrm{SAC}$-based (red) and Pt/C-IrO2-based (black) Zn-air battery. Inset of $\mathrm{g}$ showing the first and last ten runs of the charge-discharge curves for $\mathrm{Ru}-\mathrm{Cl}-\mathrm{N} \mathrm{SAC}$-based $\mathrm{Zn}$-air battery. h Optical image of the Ru-Cl-N SAC-based overall water splitting electrolyzer cell driven by two Ru-Cl-N SAC-based Zn-air battery in series. 


\section{Supplementary Files}

This is a list of supplementary files associated with this preprint. Click to download.

- Slrevision.docx

- MovieS1.mp4

- MovieS2.mp4 